\title{
Invited Commentary: Positive Youth Development and Human Complexity
}

\author{
Reed W. Larson · Steve P. Tran
}

Received: 18 February 2014/ Accepted: 17 March 2014/Published online: 30 April 2014

(C) Springer Science+Business Media New York 2014

\begin{abstract}
The process of positive development for adolescents includes struggling to address a wide variety of complex, often unstated bio-psycho-social-cultural challenges. These include formulating workable values, learning self-regulation, preparation for adult work roles-and innumerable other un-tidy puzzles. Variable-based research can only scratch the surface of how youth go about these processes; nonetheless, systematic longitudinal research like this can provide valuable information about developmental pathways and directions of change. Highlights from these papers include the finding that older youth report more goals aimed at meaningful connection with others and contributing to society; yet also that moral character did not differ by age. The papers suggest that relationships adults, hope, school engagement, participation in out-of-school programs, and intentional self-regulation can serve as mediators of positive development. Yet, a striking finding was that comparatively few youth in the study manifest a pattern of change marked by the coupling of increases in positive youth development and decreases in risk/problem behavior. We believe there is much beneath the surface to be uncovered.
\end{abstract}

Keywords Positive youth development - Developmental tasks $\cdot$ Strengths perspective $\cdot$ Developmental pathways

\section{Introduction}

The contributions of Rich Lerner, Jackie Lerner, and their collaborators to our knowledge of human development have been large. These contributions include at least two domains

R. W. Larson $(\bowtie) \cdot$ S. P. Tran

University of Illinois, Urbana-Champaign, IL, USA

e-mail: larsonr@illinois.edu (a third is Rich's prodigious work as editor of numerous research volumes). First, Rich Lerner $(2002,2006)$ has expanded Bronfenbrenner, bio-ecological systems theory to provide a more comprehensive multidisciplinary framework for the field of developmental science. This framework situates the processes of human development within a complex nested array of biological, psychological, social, community, cultural, and other relational systems. An important message is that development is not simple. It occurs within and between numerous systems at multiple levels of analysis. Second, the Lerners and their team have made many valuable empirical contributions, most recently developing and testing their PYD model. The completion of this eighth wave of the 4-H study is a significant milestone in this work of tracking how a cohort of millennial youth are navigated their way toward adulthood.

\section{Our Perspective on Positive Youth Development}

As commentators, we were invited to look at the contributions in this latest volume from our theoretical framework. I (Reed) and my collaborators-among whom Steve Tran is now an important contributor-have learned from and have many points of intersection with the Lerners' work. A priority in my research on positive youth development, borrowed from Rich Lerner (and Piaget, Dewey, and other forefounders) is understanding the role young people play as creative "producers" of their own development (Larson 2000; Lerner and Busch-Rossnagel 1981). Alone and through conversations with others, youth are conscious agents developing knowledge, skills, and values for making their way in a complex world.

In the last few years I have become increasingly focused on how challenging and difficult this process is, especially 
in the world of the 21st century (Larson et al. 2002a; Larson et al. 2009). The complex manifold of nested relational systems that Rich Lerner has identified add up to create an enormously variegated world for adolescents to understand and learn to navigate.

\section{Developmental Challenges}

As a result of this deep complexity, producing one's own development requires young people to address a wide variety of-often unstated-bio-psycho-social-cultural challenges. These include basic "developmental tasks" first introduced by earlier theorists (Erikson 1950; Havighurst 1953). These tasks-Who am I?, what are my values?, learning self-regulation, achieving autonomy-with-connection with family, and preparation for adult work roles-consist of un-tidy puzzles that adolescents need to figure out. Many involve working out tensions and contradictions (e.g., personal desire with morality, reconciling obligations to self vs. to other).

In the 21 st century young people-including the $4-\mathrm{H}$ Study youth-face added developmental challenges associated with growing up in increasing fluid and heterogeneous societies. As adolescents awaken from the protective shell of childhood, their daily lived experiences confront them with more complex worlds, with more contractions and challenges. More so than in the past, they must learn to function navigating multiple life worlds-institutional, cultural, religious, generational, digital—each with different codes, assumptions, goals, and meanings (Larson et al. 2012; Larson et al. 2002b).

As we said, the developmental tasks and challenges that adolescents face are often unstated. Youth experience them as "unstructured problems." Part of the task for young people is formulating what the tasks are: what do they need to figure out to function comfortably and effectively-in high school, a new social media site, in a romantic relationship, etc.? This complicated array of developmental challenges, we theorize, makes positive development more difficult than most adults typically acknowledge-including adolescent researchers (Larson 2011). To understand young people's positive development, I argue, it is essential for researchers to engage with the complexity of these developmental challenges.

\section{What Develops in Positive Development?}

This, too, is a difficult question. And, for me it is related to the challenges they face. The field recognized that the endpoints of positive development entails numerous dimensions: socio-emotional, cognitive, ethical, civic, spiritual, etc. (Eccles and Gootman 2002; Lerner et al. 2009). From my "complexity" viewpoint, however, what youth develop is not adequately conceptualized as linear variables (with alphas $>.70$ ), but as eclectic skill sets and dispositions. These skills sets and dispositions include abilities to understand and navigate the many difficult developmental challenges and tasks associated with coming of age in complex societies. They involve developing workable answers to puzzles-abilities to adapt to the contradictions and incongruities that youth encounter. They also involve abilities to code shift- to adapt to the different rules and values associated with different contexts (family, school, media, work settings) in consistent ways.

Our research begins to suggest what these eclectic skill sets look like. We have been studying development within one context, high quality youth programs, a setting we think provides beneficial conditions for youth to be producers of positive development (and for researchers to study how it occurs). Our findings were derived with qualitative research and we are now moving to mixed methods. What we find is that youth gain networks of insights on how to navigate different types of small and larger challenges, such as: the challenges of working in teams (e.g., coordinating self, other, and group; Larson 2007; Perry 2013); the puzzles of emotional processes (e.g., learning to understand and even use the powerful effects have on cognition, motivation, and self; Larson and Brown 2007; Rusk et al. 2013); and the challenges of working to reach positive individual or collective goals in complex and sometimes disorderly real-world contexts (Larson and Angus 2011).

This idea of development involving not variables, but skill sets is consistent with historically evolving views of cognitive development. Piaget argued that adolescents acquire a finite number of new centralized operations. But connectionist models suggest that learning entails acquisition of web of many insights, heuristics, strategies, etc., often learned in relationship to specific contexts and experiences (Fischer and Bidell 2006). This development of "webs" is not just cognitive; it includes developing dispositions, moral positions, and emotional sensibilities. ${ }^{1}$

\footnotetext{
${ }^{1}$ It also is essential to recognize that much of development is not conscious. The trillions of neurons in the human brain undergo ongoing processes of forming associations and pruning. We are intrigued, however, by new ideas that "multi-scale brain systems" work in coordination: that the functioning of higher level systems occurs on a foundation of prior associations and learning encoded outside of consciousness at these lower levels (Kinsbourne and Jordan 2009). We also note that the enormous amount of research that human brain subject to numerous blind spots, fallacies, and dispositions to bias. Humans are far from being entirely rationale creatures. Nonetheless, we think, the general task of positive development is to learn to navigate a complex existence-including both the external world and one's internal psychology with the limited tools of the human brain (Larson 2011).
} 
The Importance of Quantitative Longitudinal Research

In sum, our complexity viewpoint suggests that positive youth development is a vast and complex topic, one that is not readily reducible to variables. It involves youth trying to solve puzzles and figure out how to navigate difficult challenges. Coming from this perspective, we approached the current volume with the question: What contributions can variable-oriented longitudinal research make to understanding these complex developmental processes? Such research is vitally important. We believe there is a lot that cannot be easily measured-for example, that the $6 \mathrm{Cs}$ represent a very simplified proxy for adolescents' complex processes of addressing complex developmental tasks and challenges. Yet quantitative methods provide essential tools for examining the patterns and complexity of that which can be measured. (And qualitative methods have well-recognized limitations). Quantitative studies are the backbone of development science.

\section{The 4-H Study: Evaluating the Lerner's PYD Model}

The 4-H Study was designed with the goal of analyzing how environmental assets and other factors influence positive development. The aims include understanding the bidirectional individual $\leftarrow \rightarrow$ context relationships that contribute to this development. The study contains many elements that are a model for all quantitative developmental research, such as:

- Approaching youth development from a strengths perspective; measuring strengths as independent variables, mediators, and outcomes.

- Including measures of diverse positive outcome variables.

- Examining development ecologically, at occurring not just at an individual level but in reciprocal relationships in different contexts.

We focused on three types of contributions made by the papers: (1) examining age differences, (2) evaluating mediators of developmental processes, and (3) identifying differing developmental pathways. (Note: We understand that this shortly after completion of the 8th wave of such a large study, the authors may just be making initial forays into the data.)

\section{Age Differences}

Examining age trends is a foundational strategy of developmental science, and the new cognitive-brain potentials of adolescence make this an especially important age period for expecting age trends. The new executive suite of cognitive skills in adolescence is thought to potentiate development of powerful advanced self-regulation and social relational skills; so one might expect increases in indicators of positive development across this period (Larson 2011; Lerner et al. 2012). Indeed, qualitative research suggests that these new cognitive potentials facilitate teens' development of abilities to formulate complex challenges, think strategically, understand the abstract dynamics of emotions (Larson 2011), and learn to spot and manage their own information processing biases (Kirshner et al. 2011).

Do these 4-H data show evidence of age increases in indicators of positive development? The qualitative data analyzed by Hershberg et al. suggests that with age youth have higher moral ambitions. At older ages, they report having less egocentric and more abstract personal goals; more youth seek to form meaningful connection with others and contribute to society (although boys showed low investment in the later). But ambition is not the same as mastery—as achieving these ends.

Evidence here of age trends in achieved positive developmental is mixed. Hillard et al. found that a measure of civic character increased slightly by Wave 6 , but a measure of moral character did not differ across waves. But does this mean that development of moral character is on hold across this age period? We suggest there may be another explanation: that as youth get older and have contact with a wider world, they confront more complex and difficult moral challenges. For example, with age adolescents are exposed to greater real-world ambiguity, including competing cultural and moral codes. They may also experience more opportunities in daily life to engage in tempting amoral behaviors. Thus, although these teens appear to be running in place-showing no change on these measures-many may be making important strides by sustaining their moral character while adapting to increasingly difficult moral challenges.

This developmental experience of youth being pulled in more different directions with age is suggested by intriguing finding in the Arbeit et al. paper. Some older youth appear to have greater contradictions in their moral character. Latent class analyses, conducted at different ages, found that among older (but not younger) adolescents, Confidence and Competence scores were associated not only with the low risk profile, but also with the Alcohol and Aggression. Although this age difference was not directly tested, these findings demonstrate the plasticity of development: positives and negatives can exist side-byside. We suggest that as youth get older, and face more complexity and contradictions, some youth may adapt by tolerating personal contradictions. The authors make the interesting suggestion that this may be a group of at-risk youth who could be more easily influenced to overcome 
their antisocial and risk behavior. We look forward to further longitudinal examination of age trends in these data.

\section{Mediators of Positive Development}

The study of mediators is at the heart of PYD, especially its contributions to practice. We think of mediators as facilitating "catalytic processes": enabling, supporting, and amplifying youth's active processes of positive development. Just as risk factors can feed vicious cycles of stress and problem behavior, catalysts create fertile conditions for young people's cycles of positive development. In chemistry, a catalyst reduces the energy required for a chemical transition to occur, thus makes it more likely. Similarly, we think of mediators as creating conditions that facilitate developmental changes, for example that create conditions to help youth think through complex developmental challenges.

This volume examines important mediators that may serve this role as catalysts of positive development: constructive relationships with parents and non-parental adults (Bower et al.), hope (Callina et al.), school engagement (Chase et al., this volume), and participation out-of-school programs (Agans et al., this volume). Another set of important mediators in the 4-H Study is intentional selfregulation. Each is intriguing. Several findings here point to how these mediators serve as catalysts.

Chase et al.'s findings indicate that school engagement has a bidirectional relationships with academic success. This suggests a self-sustaining, positive feedback cycle: engagement and success reinforce each other. Research also shows that intrinsic motivation, one component of engagement, is a psychological state that (without requiring added energy) can serve as a catalyst by increasing and sustaining a person's psychological engagement in learning, which in turn increases the depth of youth's learning (rather than superficial memorizing, youth engage with and learn about the underlying processes and multi-leveled structure entailed in that domain of learning; Larson and Rusk 2011). Chase et al. take this further, theorizing that adolescents' development of skills for self-regulation (behavioral, emotional, cognitive-and possibly motivational) may be part of the catalytic mechanism at work here, a valuable hypothesis for future research.

We can also think of settings as catalysts-or, as contexts in which multiple catalysts work together. Agans et al.'s (this volume) findings reinforce increasing evidence that high quality after-school programs are settings that facilitate positive development; this may be related to a combination of catalysts: facilitative leaders, positive peer relationships, and agentic activities. (Lerner et al. 2012; Vandell et al., in press). Agans et al. find that participation in programs is consistently associated with higher PYD and Contribution across age.

To contribute further to policy and practice we will need to go beyond identifying and testing mediating variables to understanding the underlying catalytic processes. Research is needed to learn about what happens inside the "black box" of schools and of effective programs. For example, what are the strategies of youth professionals (teachers, principals, program leaders) that facilitate youth's active processes of figuring out challenges and producing their own development? Longitudinal studies of after school programs have identified a number of staff characteristics that mediate outcomes (e.g., staff training and education, staff-child ratios; Vandell et al., in press). Our lab and others are asking, What are the staff practices that support youth's daily developmental experiences (Hamilton, in press; Hirsch et al. 2011; Walker and Larson 2012)?

\section{Developmental Pathways}

Another important contributor of longitudinal research is identification of different developmental pathways. Of course, the possible pathways are as varied as the number of adolescents on the planet. So the question is whether there are identifiable profiles of youth-profiles that are indicative of common developmental routes. Several papers in this volume use latent class analysis or latent profile analysis to identify different groups (Arbeit et al.; Bowers et al.; Callina et al.; Geldhof et al.)

These analyses are interesting because some of the profiles that emerged fit into existing theoretical models while others do not. For example, in the Bowers et al. article, profiles emerged that fit into the traditional parenting categories (e.g., authoritarian, permissive, authoritative), but they also discovered other profiles that did not fit (e.g., controlling, school-focused, integrative). Youth with "positive" parenting profiles like authoritative parenting reported higher likelihoods of having non-parental adults for support. Yet the youth who perhaps need it the most (those with "problematic" parenting profiles, i.e., school-focused, authoritarian, uninvolved, and controlling) were less likely to have non-parental adults for support. However, it is intriguing that the youth with these problematic profiles, when they do have a non-parental figure, report higher scores for several of the six Cs (e.g., for character). These findings demonstrate that PYD can be accomplished through a variety of pathways. Some youth with difficult parent relationships find resources from other contexts of their lives that may help them navigate developmental challenges, become resilient, and still achieve positive outcomes.

Perhaps the most striking finding is how many youth are in trajectories (i.e. are in profiles) that are not consistent 
with positive development. J. Lerner et al. (2012) report that only one-sixth of the youth in the sample manifested a pattern of change marked by the coupling of increases in positive youth development and decreases in risk/problem behavior. As we have argued, this should not be surprising. The developmental challenges and tasks of adolescence are hard! Longitudinal analyses will be needed to better sort out what is happening for different groups of youth over time (independently of their initial categorization) and search for clues as to how positive development can occur and can be supported for all groups of youth.

\section{Contributions and Future Directions}

We have not reviewed the many prior findings from the 4-H Study, but they contain much else on age trends, mediators, and longitudinal relationships. Suffice it to say that the study has made valuable contributions and promises much more. The Lerners' PYD model provides a rich framework for many further analyses.

From our perspective, the findings in this volume also confirm how complex human development is. Longitudinal quantitative studies keep us honest (qualitative researchers take note)! Many relationships expected from these data didn't pan out. We have noted the absence of some expected age difference, and Arbeit et al.'s finding that positive developmental variables can co-occur with problem behaviors. Agans et al. also observe that high levels of participation in after school programs was more strongly linked to depressive symptoms at some age periods than others. The findings provide interesting illustrations of the plasticity of development and the many questions for future research.

We conclude by pointing to the need for more research on positive development with diverse samples, methods, and conceptual frameworks. To flourish, the study of positive development needs to include studies that allow for more understanding of culture, ethnicity, and historic context. This requires studies that have a critical mass of non-Euro-Americans and opened methods that allow for cultural differences in developmental priorities and processes to emerge. We need to understand more about the developmental challenges faced across different ecological contexts and settings, and for youth with differing abilities' and subject to different risk factors. From our perspective, there is much more need for ethnographic, qualitative, and mixed methods studies to understand the processes of positive development in the context daily contexts of youth's lived experience-as they experience and create it. There is also much need for research on the roles of adult youth practitioners, peers and others in contributing to these developmental processes. That said, we see the findings in this volume and the PYD model as valuable steps in the shared effort to understand, support, and cultivate the strengths of young people.

Author contributions ST read and critiqued the journal articles and provided input on the draft of this article. RL scanned the articles, integrated the critiques, and placed the findings in the larger theoretical and methodological context. Both authors read and approved the final manuscript of this article.

\section{References}

Eccles, J., \& Gootman, J. (2002). Community programs to promote youth development. Washington, DC: Committee on Community-Level Programs for Youth. Board on Children, Youth, and Families, National Research Council and Institute of Medicine.

Erikson, E. (1950). Childhood and society. NY: Norton.

Fischer, K. W., \& Bidell, T. R. (2006). Dynamic development of action and thought. In W. Damon \& R. M. Lerner (Eds.), Handbook of child psychology (6th ed., Vol. 1, pp. 313-399). Hoboken, NJ: Wiley.

Hamilton, S. F. (Ed.) (in press). Applied developmental science on linking research to the practice of youth development (Special Issue). Applied Developmental Science.

Havighurst, R. J. (1953). Human development and education. NY: McKay.

Hirsch, B., Deutsch, N., \& DuBois, D. (2011). After-school centers and youth development. Cambridge, UK: Cambridge University Press.

Kinsbourne, M., \& Jordan, S. J. (2009). Embodied anticipation: A neuro developmental interpretation. Discourse Processes, 46, 103-126.

Kirshner, B., Pozzoboni, K., \& Jones, H. (2011). Learning to manage bias: A case study of youth participatory action research. Applied Developmental Science, 15, 140-155.

Larson, R. W. (2000). Towards a psychology of positive youth development. American Psychologist, 55(1), 170-183.

Larson, R. W. (2007). From "I" to "We": Development of the capacity for teamwork in youth programs. In R. Silbereisen \& R. M. Lerner (Eds.), Approaches to positive youth development (pp. 277-292). Thousand Oaks, CA: Sage.

Larson, R. W. (2011). Positive development in a disorderly world: SRA presidential address. Journal of Research on Adolescence, 21, 317-334.

Larson, R. W., \& Angus, R. M. (2011). Adolescents' development of skills for agency in youth programs: Learning to think strategically. Child Development, 82, 277-294.

Larson, R. W., \& Brown, J. R. (2007). Emotional development in adolescence: What can be learned from a high school theater program. Child Development, 78, 1083-1099.

Larson, R. W., Brown, B. B., \& Mortimer, J. (Eds.) (2002a). Adolescents' preparation for the future: Perils and promise [special issue]. Journal of Research on Adolescence, 12 (1), $1-166$.

Larson, R. W., Jensen, L., Kang, H., Griffith, A., \& Rompala, V. (2012). Peer groups as a crucible of positive value development in a global world. In G. Trommsdorff \& X. Chen (Eds.), Values, religion, and culture in adolescent development (pp. 164-187). New York: Cambridge University Press.

Larson, R. W., \& Rusk, N. (2011). Intrinsic motivation and positive development. In R. M. Lerner, J. V. Lerner, \& J. B. Benson (Eds.), Advances in child development and behavior: positive youth development, 41 (pp. 89-130). Oxford, UK: Elsevier. 
Larson, R. W., Wilson, S., Brown, B. B., Furstenberg, F. F., \& Verma, S. (2002b). Changes in adolescents' interpersonal experiences: Are they being prepared for adult relationships in the $21 \mathrm{st}$ century? Journal of Research on Adolescence, 12(1), 31-68.

Larson, R. W., Wilson, S., \& Rickman, A. (2009). Globalization, societal change, and adolescence across the world. In R. M. Lerner \& L. Steinberg (Eds.) Handbook of Adolescent Psychology, Vol 2, 3rd Edition (pp. 590-622). New York: Wiley.

Lerner, R. M. (2002). Concepts and theories of human development (3rd ed.). Mahwah, NJ: Erlbaum.

Lerner, R. M. (2006). Developmental science, developmental systems and contemporary theories of human development. In R. M. Lerner (Ed.) Theoretical models of human development (pp. 1-17). Vol 1. In W. Damon \& R. M. Lerner. Handbook of child psychology (6th ed) Hoboken, NJ: Wiley.

Lerner, J. V., Bowers, E. P., Minor, K., Boyd, M. J., Mueller, M. K., Schmid, K. L., Lerner. R. M. (2012). Positive youth development: Processes, philosophies, and programs. In: Handbook of Psychology. Developmental Psychology. 2nd Edition, New York: Wiley.

Lerner, R. M., \& Busch-Rossnagel, N. (1981). Individuals as producers of their development. New York: Academic Press.

Lerner, J. V., Phelps, E., Forman, Y., \& Bowers, E. (2009). Positive youth development. In R. M. Lerner \& L. Steinberg (Eds.), Handbook of adolescent psychology (3rd ed., Vol. 1, pp. 524-558). Hoboken, NJ: Wiley.

Perry, S. C. (2013). How teens learn to work together: Collaborative processes of development at camp. (Unpublished
Master's thesis). University of Illinois at Urbana-Champaign. Urbana, IL.

Rusk, N., Larson, R. W., Raffaelli, M., Walker, K. C., Washington, L., Gutierrez, V., et al. (2013). Positive youth development in organized programs: How teens learn to manage emotions. In C. Proctor \& P. A. Linley (Eds.), Positive psychology: Research, applications and interventions for children and adolescents (pp. 247-261). New York: Springer.

Vandell, D. L., Larson, R. W., Mahoney, J. L., \& Watts, T. W. (in press). Children's organized activities. In Bornstein, M. H., Leventhal, T., \& Lerner, R. M. (Eds.) Handbook of child psychology and developmental science, 7th Ed., Vol. 4: Ecological settings and processes in developmental systems. New York: Wiley.

Walker, K. C., \& Larson, R. W. (2012). Youth worker reasoning about dilemmas encountered in practice: Expert-novice differences. Journal of Youth Development, 7(1), 6-21.

Reed W. Larson is a professor in the Departments of Human and Community Development, Psychology, and Educational Psychology at the University of Illinois at Urbana-Champaign. His research focuses on the daily developmental experience of adolescents, particularly in the context of youth development programs and families.

Steve P. Tran is a doctoral student in the Department of Human and Community Development at the University of Illinois at UrbanaChampaign. His major research interests in immigrant and ethnic minority families and communities, immigration, and globalization. 